\title{
Hypercholesterolemia Is Associated with a T Helper (Th) $1 /$ Th2 Switch of the Autoimmune Response in Atherosclerotic apo E-knockout Mice
}

\author{
Xinghua Zhou, Gabrielle Paulsson, Sten Stemme, and Göran K. Hansson \\ Centre for Molecular Medicine, Karolinska Institute, S-17176 Stockholm, Sweden
}

\begin{abstract}
Atherosclerosis is an inflammatory-fibrotic response to accumulation of cholesterol in the artery wall. In hypercholesterolemia, low density lipoproteins (LDL) accumulate and are oxidized to proinflammatory compounds in the arterial intima, leading to activation of endothelial cells, macrophages, and $\mathrm{T}$ lymphocytes. We have studied immune cell activation and the autoimmune response to oxidized LDL in atherosclerotic apo E-knockout mice. Autoantibodies to oxidized LDL exhibited subclass specificities indicative of $T$ cell help, and the increase in antibody titers in peripheral blood was associated with increased numbers of cytokine-expressing $T$ cells in the spleen. In addition to $T$ cell-dependent antibodies, IgM antibodies to oxidized LDL were also increased in apo E-knockout mice. This suggests that both $\mathrm{T}$ cell-dependent and $T$ cell-independent epitopes may be present on oxidized LDL. In moderate hypercholesterolemia, IgG antibodies were largely of the IgG2a isotype, suggesting that $\mathrm{T}$ cell help was provided by proinflammatory $\mathrm{T}$ helper $(\mathrm{Th})$ 1 cells, which are prominent components of atherosclerotic lesions. In severe hypercholesterolemia induced by cholesterol feeding of apo E-knockout mice, a switch to Th2dependent help was evident. It was associated with a loss of IFN- $\gamma$-producing Th1 cells in the spleen, whereas IL-4-producing Th 2 cells were more resistant to hypercholesterolemia. IFN- $\gamma$ but not IL-4 mRNA was detected in atherosclerotic lesions of moderately hypercholesterolemic apo E-knockout mice, but IL-4 mRNA appeared in the lesions when mice were made severely hypercholesterolemic by cholesterol feeding. These data show that IFN- $\gamma$-producing Th1 cells infiltrate atherosclerotic lesions and provide $T$ cell help for autoimmune responses to oxidized LDL in apo E-knockout mice. However, severe hypercholesterolemia is associated with a switch from Th1 to Th2, which results not only in the formation of IgG1 autoantibodies to oxidized LDL, but also in the appearance of Th2-type cytokines in the atherosclerotic lesions. Since the two subsets of $T$ cells counteract each other, this switch may have important consequences for the inflammatory/immune process in atherosclerosis. (J. Clin.
\end{abstract}

Address correspondence to Dr. Göran K. Hansson, Centre for Molecular Medicine L8:03, Karolinska Hospital, S-17176 Stockholm, Sweden. FAX: 46-8-313147; E-mail: goran.hansson@cmm.ki.se

Received for publication 16 July 1997 and accepted in revised form 18 February 1998.

J. Clin. Invest.

(C) The American Society for Clinical Investigation, Inc. 0021-9738/98/04/1717/09 \$2.00

Volume 101, Number 8, April 1998, 1717-1725

http://www.jci.org
Invest. 1998. 101:1717-1725.) Key words: autoantibodies • atherosclerosis - cytokines - lipoprotein oxidation • T lymphocytes

\section{Introduction}

Lipoprotein oxidation seems to play a key role in the development of atherosclerosis. Low density lipoproteins (LDL) are oxidized in tissues including the artery wall, releasing oxidation products that activate an inflammatory response $(1,2)$. For instance, lysophosphatidylcholine and oxidized sterols may activate macrophages and endothelial cells to generate oxygen radicals and express adhesion molecules (3-7). This increases LDL oxidation and leads to recruitment of immune cells to the arterial intima $(4,5)$. Macrophages internalize oxidized (ox) ${ }^{1}$ LDL via their scavenger receptors and transform into foam cells (8). T cells recruited to the lesion recognize epitopes on oxLDL presented to them by the macrophages and initiate an immune response (9). By secretion of cytokines, this may affect many different aspects of atherogenesis, including oxLDL uptake, radical production, adhesion molecule expression, smooth muscle proliferation, and vascular contractility. Thus, significant effects on atherosclerosis and ischemic heart disease have been reported in immunodeficient experimental animals and humans, respectively (10-16).

The immune response against oxLDL results in antibody production $(17,18)$. High titers of anti-oxLDL antibodies are found in atherosclerotic patients and in experimental animals with hypercholesterolemia (18-25). Both IgM and IgG antibodies are generated, suggesting that both $\mathrm{T}$ cell-dependent and -independent pathways for B cell activation are involved in the immune response against oxLDL (21).

The development of murine models permits a dissection of immune mechanisms in atherosclerosis. Mice with a targeted disruption of the apo $\mathrm{E}$ gene $\left(\mathrm{E}^{0}\right.$ mice) develop severe atherosclerosis that progresses from fatty streaks to fibrofatty plaques and advanced lesions (26-28). There is a prominent immune component in these lesions, with a dominance of macrophages and $\mathrm{CD}^{+} \mathrm{T}$ cells (29).

Crossbreeding of $\mathrm{E}^{0}$ mice with immunodeficient knockout mice has revealed that $\mathrm{T}$ and $\mathrm{B}$ cell-deficient mice exhibit reduced atherosclerosis $(12,30)$. However, the importance of immune cells is reduced in severe hypercholesterolemia (12). A more detailed dissection of the immune component indicates that IFN- $\gamma$ responses accelerate atherosclerosis severely (11), suggesting that the IFN- $\gamma$-producing T helper (Th) subset of T cells is proatherogenic.

$\mathrm{E}^{0}$ mice develop high titers of anti-oxLDL antibodies (31). Hybridomas generated from their spleens secrete both IgM and IgG antibodies that recognize oxidation-induced epitopes on LDL (21). The most common of these epitopes are alde-

1. Abbreviations used in this paper: $\mathrm{E}^{0}$, apo $\mathrm{E}-\mathrm{knockout}$ MDA, malondialdehyde; ox, oxidized; RT, reverse transcription; Th, T helper. 
hydes conjugated to lysine residues, particularly malondialdehyde (MDA)-lysine (21). Such aldehydes are formed during lipid peroxidation, and antibodies with the same specificity are found also in patients with atherosclerosis $(18,32)$.

Whereas B cells can detect a variety of small molecules such as MDA-lysine, T cells usually recognize oligopeptides associated with major histocompatibility molecules $(33,34)$. Therefore, the role of $\mathrm{T}$ cells in autoantibody responses to oxLDL, if any, has been unclear. B cells can produce antibodies without $\mathrm{T}$ cell help, and the high titer of IgM antibodies to oxLDL (21) may reflect $\mathrm{T}$ cell-independent B cell activation. However, the maturation of antibody responses requires $\mathrm{T}$ cell help (35). In the mouse, production of IgG1 antibodies depends on help by Th2-type $\mathrm{CD}^{+} \mathrm{T}$ cells, whereas switching from IgM to IgG2a requires Th1 help. Both types of help involve secretion of specific T cell cytokines: Th2 cells make IL-4, IL-6, and others, whereas Th1 cells secrete IFN- $\gamma$ (35).

To evaluate the role of $\mathrm{T}$ cells in autoimmune responses to oxLDL in atherosclerosis, we have analyzed anti-MDA-LDL antibodies and $\mathrm{T}$ cell cytokines during disease progression in $\mathrm{E}^{0}$ mice. We found evidence for $\mathrm{T}$ cell help with production of Th1-dependent IgG2a antibodies that peak during the fatty streak phase and with secretion of IFN- $\gamma$ both in the spleen and in the plaque itself. However, severe hypercholesterolemia was associated with a switch towards a Th2-driven response, with increasing numbers of IL-4-producing Th2 cells in the spleen, a dominance of IgG1 anti-MDA-LDL in the circulation, and the appearance of IL-4 transcripts in the plaque. These data show that $\mathrm{T}$ cell activation and the $\mathrm{T}$ cell help to autoantibody production depend on the cholesterol level. The type of immune activation may affect the molecular events governing the progression of atherosclerosis, and our data could explain why the importance of immune defects seems to vary with the plasma cholesterol level in $\mathrm{E}^{0}$ mice (12).

\section{Methods}

Animals. Male $\mathrm{E}^{0}$ mice (27) bred into a C57BL/6 background (strain C57BL/6J-Apoe ${ }^{\text {tm1 Unc }}$ ) were obtained from The Jackson Laboratory (Bar Harbor, ME). 8-wk-old mice were fed either a pelleted high cholesterol diet with $1.25 \%$ cholesterol (see below), a "Western" diet with $0.15 \%$ cholesterol, or normal mouse pelleted chow. Normal male C57BL/6 mice were obtained from Charles River Sverige AB, (Uppsala, Sweden) and fed normal chow. Blood was obtained from the tail vein of live mice and by heart puncture in conjunction with killing. Mouse sera were centrifuged at 14,000 $\mathrm{g}$ for $30 \mathrm{~min}$ to remove chylomicrons and stored at $-80^{\circ} \mathrm{C}$. Groups of four to six animals were killed in carbon dioxide after 5, 10, or $15 \mathrm{wk}$ of diet treatment.

Diets. The high cholesterol and Western diets were prepared as pellets by AnalyCen (Linköping, Sweden). The high cholesterol diet contained $25.7 \%$ protein and $8.75 \%$ fat and was based on corn starch, casein, glucose, sucrose, cocoa butter, cellulose, minerals, cholesterol, and a vitamin mix. The cholesterol content was $1.25 \%$, cholic acid was $0.5 \%$, and the energy content was $14.3 \mathrm{MJ} / \mathrm{kg}$. The Western diet included $21 \%$ fat and was also based on corn starch, casein, glucose, saccharose, cocoa butter, cellulose, minerals, cholesterol, and a vitamin mix without sodium cholate. The cholesterol level was $0.15 \%$. The normal mouse chow (Brood stock feed R3) was purchased from B \& K Universal AB (Sollentuna, Sweden). It contained 5.0\% fat, with $<0.05 \%$ cholesterol and an energy content of $13.0 \mathrm{MJ} / \mathrm{kg}$.

Serum cholesterol analysis. The cholesterol concentration in mice sera was determined using a cholesterol oxidase-based method (Merck Diagnostica, Darmstadt, Germany) and an Ultrolab system (Beckman Instruments, Inc., Fullerton, CA).
Lipoprotein isolation. Venous blood was obtained from healthy human donors after an overnight fast and pooled into vacuum tubes containing $\mathrm{Na}_{2}$ EDTA $(1 \mathrm{mg} / \mathrm{ml})$. LDL was isolated from plasma by ultracentrifugation through a discontinuous $\mathrm{NaCl}$ gradient of 1.020 $1.063 \mathrm{mg} / \mathrm{ml}$ for $16 \mathrm{~h}$ at $4^{\circ} \mathrm{C}$ in an L8-80 ultracentrifuge (Beckman Instruments, Inc.) using a $50.3 \mathrm{Ti}$ fixed-angle rotor (Beckman Instruments, Inc.) The protein content was determined by the Lowry method, and the LDL preparation with added $\mathrm{Na}_{2}$ EDTA $(1 \mathrm{mg} / \mathrm{ml})$ was sterile filtered, kept at $4^{\circ} \mathrm{C}$ under $\mathrm{N}_{2}$, and used within $2 \mathrm{wk}$.

Modification of $L D L$. MDA was generated from malondialdehyde bis dimethylacetal (Sigma Chemical Co., St. Louis, MO) by acid hydrolysis. Briefly, a mixture of $96 \mu \mathrm{l} 4 \mathrm{M} \mathrm{HCl}, 704 \mu \mathrm{l}$ malondialdehyde bis dimethylacetal, and 3,200 $\mu \mathrm{l}$ double-distilled $\mathrm{H}_{2} \mathrm{O}$ was vortexed and incubated for $10 \mathrm{~min}$ at $37^{\circ} \mathrm{C}$. The reaction was stopped by adjusting the $\mathrm{pH}$ to 7.4 with $1 \mathrm{M} \mathrm{NaOH}$. To produce MDA-LDL (32), LDL was gel filtered on PD-10 columns (Pharmacia Biotech $\mathrm{AB}$, Uppsala, Sweden) to remove EDTA and incubated for $3 \mathrm{~h}$ at $37^{\circ} \mathrm{C}$ with $0.5 \mathrm{M} \mathrm{MDA}$ at a ratio of $100 \mu \mathrm{MDA} / \mathrm{mg} \mathrm{LDL}$. Unbound MDA was removed by gel filtration. MDA-LDL thus prepared exhibited modification of $60-65 \%$ of the lysine residues, as evaluated by the trinitrobenzene sulfonic acid assay. In addition, agarose electrophoresis and spectrofluorometry at $400 / 470 \mathrm{~nm}$ were used to confirm the MDA modification of LDL.

Antibody analysis. ELISA methods were used to quantitate serum Ig and specific antibodies of different subclasses. For analysis of total Ig isotypes, polystyrene microtiter plates were coated overnight at $4^{\circ} \mathrm{C}$ with $5 \mu \mathrm{g} / \mathrm{ml}$ of rat anti-mouse Ig capture antibodies (Table I) in a coating buffer with $100 \mathrm{mM} \mathrm{NaHCO}$ and $1 \mathrm{mg} / \mathrm{ml} \mathrm{Na}_{2}$ EDTA. Plates were then washed thoroughly with PBS with $0.05 \%$ Tween- 20 and incubated with PBS with 5\% BSA for 30 min at room temperature to prevent nonspecific binding. Mouse sera were incubated for $1 \mathrm{~h}$ at $37^{\circ} \mathrm{C}$ in duplicate wells, using a serum dilution of $1 / 100$ in PBSTween. After rinsing, conjugated antibodies to IgM, IgG, IgG2a (all alkaline phosphatase-conjugated), or IgG1 (peroxidase-conjugated) were added to the wells for a 1 -h incubation at $37^{\circ} \mathrm{C}$, plates were again washed, and enzyme activities were developed using $p$-nitrophenyl phosphate (Sigma Chemical Co.) or $o$-phenylenediamine dihydrochloride (Sigma Chemical Co.) to visualize alkaline phosphatase and horseradish peroxidase, and read at 405 and $450 \mathrm{~nm}$, respectively.

To quantitate specific antibodies, microtiter plates were conjugated with $15 \mu \mathrm{g} / \mathrm{ml}$ LDL or MDA-LDL under the same conditions as for capture antibodies described above. Plates were blocked and washed as described, and sera were added at 1/80 for analysis of IgM antibodies to LDL and MDA-LDL, $1 / 20$ for IgG, and 1/5 for IgG1 and IgG2a antibodies to LDL and MDA-LDL. Detection was performed as described above. The ratio of absorbance on plates coated with MDA-LDL divided by the absorbance on plates with native LDL was calculated to estimate antibody titers in order to correct for nonspecific binding of autoantibodies to LDL.

Immunohistochemistry. T cell cytokine expression was evaluated by immunohistochemical analysis of spleen sections (36). Fresh-frozen, air-dried sections were fixed with $2 \%$ paraformaldehyde in PBS at room temperature for $20 \mathrm{~min}$. To increase antibody access and inhibit endogenous peroxidase activity, sections were incubated for $1 \mathrm{~h}$ at room temperature in the dark with $1 \% \mathrm{H}_{2} \mathrm{O}_{2}, 2 \%$ sodium azide (Sigma Chemical Co.), 0.1\% saponin, $10 \mathrm{mM}$ Hepes in Earle's balanced salt solution (EBSS-saponin). Endogenous biotin was blocked with an avidin-biotin blocking kit (Vector Laboratories, Inc., Burlingame, CA), and the sections were washed with EBSS-saponin and incubated in a humid chamber overnight at room temperature with mAbs against IL-4, IL-10, and IFN- $\gamma$ (Table I) in EBSS-saponin using optimal dilutions determined by checkerboard titration on spleen sections. After rinsing, the sections treated with unconjugated mAbs were incubated with biotinylated rabbit anti-rat IgG (Vector Laboratories, Inc.) for $30 \mathrm{~min}$ at room temperature, rinsed, and incubated with an avidin DH/biotinylated peroxidase complex (Vector Laboratories, Inc.) for $30 \mathrm{~min}$. Sections treated with biotinylated mono- 


\begin{tabular}{llll}
\hline \multicolumn{1}{c}{ Antigen } & \multicolumn{1}{c}{ Hybridoma } & \multicolumn{1}{c}{ Antibody type } & \multicolumn{1}{c}{ Supplier } \\
\hline $\begin{array}{l}\text { Mouse IgM } \\
(\mu \text { heavy chain-specific })\end{array}$ & (Polyclonal) & AP-labeled goat & Southern Biotechnology Associates, Inc. (Birmingham, AL) \\
$\begin{array}{l}\text { Mouse IgG } \\
(\gamma \text { heavy chain-specific) })\end{array}$ & (Polyclonal) & AP-labeled goat & Southern Biotechnology Associates, Inc. \\
$\begin{array}{l}\text { Mouse IgG2a } \\
\text { Mouse IgG2a }\end{array}$ & R19-15 & AP-labeled rat IgG1 & $\begin{array}{l}\text { PharMingen (San Diego, CA) } \\
\text { Mouse IgG1 }\end{array}$ \\
$\begin{array}{ll}\text { Mouse IgG1 } \\
\text { Mouse IgG1 }\end{array}$ & LO-6.5 & Rat IgG2a & PharMingen \\
Mouse IL-10 & LO-MG1-2 & Rat IgG2a & PharMingen \\
Mouse IFN- $\gamma$ & JES5-16E3 & Biotin rat IgG2b & Serotec Ltd. (Oxford, UK) \\
Mouse IL-4 & XMG1.2 & Biotin rat IgG1 & Serotec Ltd. \\
Rat IgG & BVD4-1D11 & Rat IgG2b & PharMingen \\
& (Polyclonal) & Biotin-labeled rabbit & PharMingen \\
& & & Vector Laboratories, Inc. \\
\hline
\end{tabular}

$A P$, Alkaline phosphatase. $H R P$, Horseradish peroxidase.

clonals were subsequently incubated with avidin/biotinylated peroxidase without prior incubation with biotin-anti-rat IgG. Staining was visualized by adding a diaminobenzidine $-\mathrm{H}_{2} \mathrm{O}_{2}$ substrate solution, and sections were counterstained with hematoxylin. Controls included irrelevant, isotype-matched $\mathrm{IgG}$ and elimination of the primary antibody step. Unfortunately, the immunohistochemical methods for cytokine analysis could not be applied to atherosclerotic plaques, possibly because epitopes were masked by accumulating lipids.

Extraction of $m R N A$ and reverse transcription (RT) PCR. To explore the expression of cytokines in the atherosclerotic lesions, the heart and proximal aorta were dissected from mice at different periods on diet after perfusion with RNase-free PBS. The plaque was then separated from the proximal aorta at $4^{\circ} \mathrm{C}$ and kept at $-70^{\circ} \mathrm{C}$. The plaque mRNA was extracted using Dynabeads Oligo(dT)25 (Dynal A.S., Oslo, Norway) according to the manufacturer's protocol.

The cDNA synthesis was performed by incubating the mRNA with hexanucleotides (pdN6; Pharmacia Biotech $\mathrm{AB}$ ) at $70^{\circ} \mathrm{C}$ for $3 \mathrm{~min}$ followed by mixing on ice with $0.5 \mathrm{mM}$ each of dNTP, $5 \mathrm{mM}$ DTT, 60 U/40 $\mu$ l RNasin (Promega Corp., Madison, WI), 400 U/40 $\mu$ l Superscript II RT (Life Technologies, Inc., Gaithersburg, MD) in RT buffer, and incubating at $25^{\circ} \mathrm{C}$ for $10 \mathrm{~min}, 42^{\circ} \mathrm{C}$ for $50 \mathrm{~min}$, and $94^{\circ} \mathrm{C}$ for $4 \mathrm{~min} .1 / 20$ of the cDNA reaction was used in the subsequent PCR reaction, total volume $50 \mu \mathrm{l}$, according to the manufacturer (Life Technologies, Inc.). The cycling conditions were denaturation for $40 \mathrm{~s}$ at $94^{\circ} \mathrm{C}$, annealing for $45 \mathrm{~s}$ at $55^{\circ} \mathrm{C}$ (IL-4) or $64^{\circ} \mathrm{C}$ (IFN- $\gamma$ ), and polymerization for $1 \mathrm{~min}(\mathrm{IFN}-\gamma)$ or $1.5 \mathrm{~min}$ (IL-4) at $72^{\circ} \mathrm{C}$. Before the samples were inserted, the PCR block was preheated to $94^{\circ} \mathrm{C}$. The sequences of the primers used were as follows: IL-4, 5'-CCA GCT AGT TGT CAT CCT GCT CTT CTT TCT CG-3' (sense), and 5'CAG TGA TGT GGA CTT GGA CTC ATT CAT GGT GC-3' (antisense); IFN- $\gamma, 5^{\prime}$-TGC ATC TTG GCT TTG CAG CTC TTC CTC ATG GC-3' (sense); and 5'-TGG ACC TGT GGG TTG TTG ACC TCA AAC TTG GC-3' (antisense). Both primers were purchased from Clontech (Palo Alto, CA). As a control, we also analyzed mRNA of a "housekeeping gene," hypoxanthine phosphoribosyl transferase: 5'-CCTGCTGGATTACATTAAAGCACTG-3' (sense), 5'GTCAAGGGCATATCCAACAACAAAC-3' (antisense).

$20 \mu \mathrm{l}$ of PCR products was run on $1.7 \%$ agarose gels with a 100 -bp DNA ladder. The cDNA from lymph nodes of $\mathrm{E}^{0}$ mice, as a positive control, was prepared as above. For negative control, plaque mRNA replaced cDNA as template in the PCR to preclude the possible contamination of mRNA by genomic DNA during the process of extraction.
Statistics. Wilcoxon's nonparametric significance test was used since antibody titers did not show normal distribution. The significance level was set at $P<0.05$.

\section{Results}

Lesion development in $E^{0}$ mice. $\mathrm{E}^{0}$ mice develop atherosclerotic lesions that bear a striking resemblance to the human disease. At 18 wk of age, $\mathrm{E}^{0}$ mice fed standard mouse chow exhibited significant fatty streak lesions that were filled with macrophage-derived foam cells as well as $\mathrm{CD} 4^{+} \mathrm{T}$ cells (29). 5 wk later, these fatty streaks showed signs of progression into fibrofatty plaques, with smooth muscle infiltration and the formation of fibrous caps consisting of smooth muscle cells. The disease process was accelerated dramatically in mice fed diets with either $0.15 \%$ (Western) or $1.25 \%$ cholesterol (high cholesterol). Already at $11 \mathrm{wk}$ of age, after $3 \mathrm{wk}$ on the high cholesterol diet, large fatty streaks were detectable at the aortic sinus. After $10 \mathrm{wk}$ on the diet (18 weeks of age), these lesions had transformed into fibrofatty plaques with a smooth muscle capsule surrounding a macrophage-rich core region. As reported previously, $\mathrm{CD}^{+} \mathrm{T}$ cells were found in clusters throughout these lesions (29). In contrast to the findings in $\mathrm{E}^{0}$ mice, C57BL/6 mice fed normal chow did not exhibit any signs of atherosclerosis.

Development of antibody responses to $M D A-L D L$ in $E^{0}$ mice. Circulating antibodies to MDA-LDL were detected using an ELISA assay. We could confirm the recent report by $\mathrm{Pa}-$ linski et al. (22) that $\mathrm{E}^{0}$ mice develop high-titer antibodies to MDA-LDL (Table II). A minimal absorption to plates coated with native LDL was also observed (Table II). This could be due to oxidation of LDL in the ELISA plate, which is difficult to control, or alternatively to antibody formation to the native lipoprotein if haptenization with MDA breaks tolerance. To specifically analyze antibodies directed against the MDAmodified epitopes, we therefore divided the absorbance value for antibody binding to MDA-LDL with that of antibody binding to native LDL (Table II). This reduced the variability in the assays but did not change the tendencies observed when analyzing the absorbance data directly. Therefore, all subse- 
Table II. Autoantibodies to MDA-LDL in 13-wk-old $E^{0}$ and C57BL/6 Mice

\begin{tabular}{|c|c|c|c|c|c|c|}
\hline & IgM anti-MDA-LDL & IgM anti-nLDL & IgM ratio & IgG anti-MDA-LDL & IgG anti-nLDL & IgG ratio \\
\hline C57BL/6 & $0.068 \pm 0.023$ & $0.016 \pm 0.007$ & $4.48 \pm 1.88$ & $0.107 \pm 0.062$ & $0.053 \pm 0.046$ & $1.17 \pm 0.281$ \\
\hline $\mathrm{E}^{0}$ chow & $0.745 \pm 0.199 *$ & $0.028 \pm 0.015$ & $16.74 \pm 3.243^{*}$ & $0.779 \pm 0.328^{*}$ & $0.143 \pm 0.067$ & $5.06 \pm 1.76^{*}$ \\
\hline $\mathrm{E}^{0}$ hi-chol & $1.12 \pm 0.255^{*}$ & $0.051 \pm 0.020$ & $19.92 \pm 3.963^{*}$ & $0.602 \pm 0.100 *$ & $0.214 \pm 0.073$ & $3.70 \pm 1.26^{*}$ \\
\hline
\end{tabular}

Antibody values are $\mathrm{A}_{405}$ in ELISA assays of $\mathrm{IgM}$ and IgG antibodies to MDA-LDL and native $(n)$ LDL. Ratios are anti-MDA-LDL ( $\left.\mathrm{A}_{405}\right) /$ antinLDL $\left(\mathrm{A}_{405}\right)$. Mean \pm SEM, $n=6$. * Significant difference vs. C57BL/6, $P<0.05$. hi-chol, High cholesterol diet.

quent results are presented as absorbance ratios, in analogy with previous work (e.g., 22).

$\mathrm{E}^{0}$ mice rapidly developed $\mathrm{IgM}$ antibodies to MDA-LDL (Table II, and Fig. 1). Titers peaked at $13 \mathrm{wk}$ of age in chowfed as well as in cholesterol-fed $\mathrm{E}^{0}$ mice (Fig. 1). Similarly, IgG
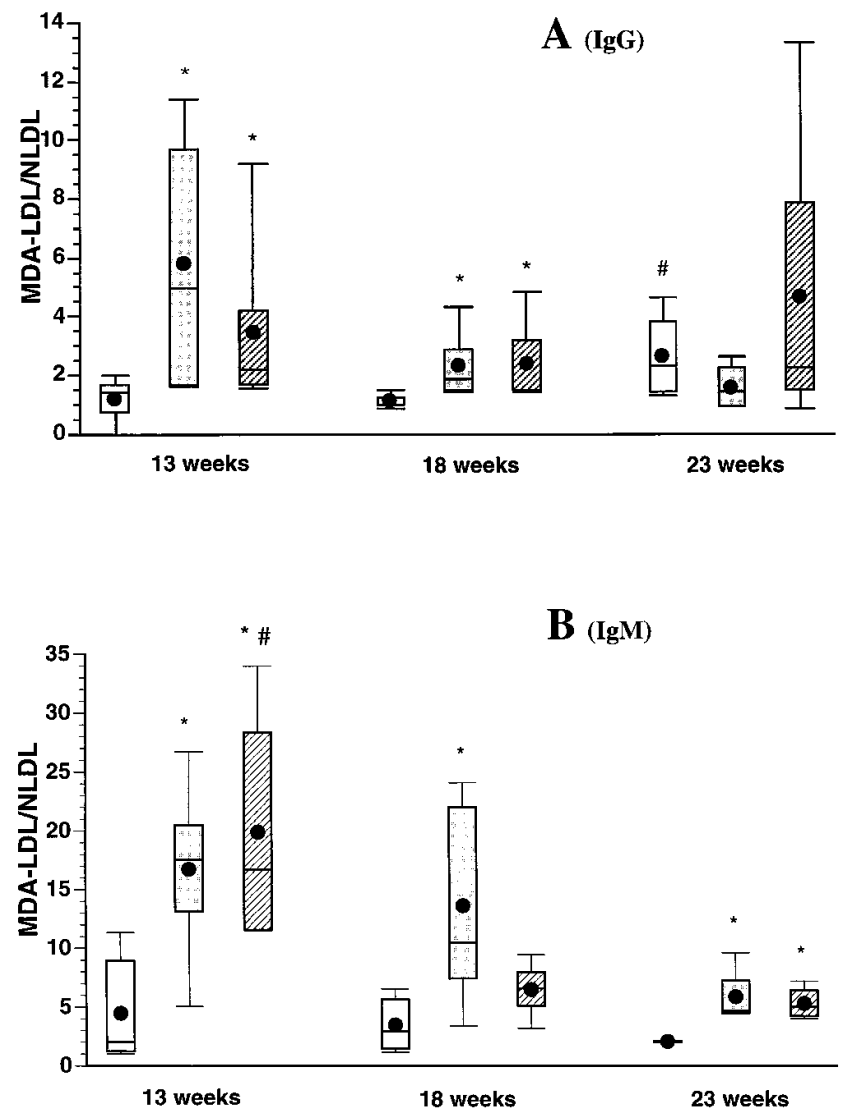

Figure 1. Box plots showing the titer of $\operatorname{IgG}(A)$ and $\operatorname{IgM}(B)$ antibodies to MDA-LDL. Sera were collected at the indicated age from C57BL/6 mice fed normal chow (white bars), and from $\mathrm{E}^{0}$ mice fed normal chow (gray bars) or a high cholesterol diet (striped bars). The top, bottom and line through the middle of the box correspond to the 75th, 25th, and 50th percentile (median), respectively. The dot in the middle of the box represents the mean. The whiskers at the top and bottom of the box extend from the 90th and 10th percentile, respectively. $n=6$ for each group at each time point. ${ }^{*} P<0.05$ vs. C57BL/6 group. In $A,{ }^{\#} P<0.05$ vs. C57BL/6 group at 13 and $18 \mathrm{wk}$ of age. In $B,{ }^{\sharp} P<0.05$ vs. $\mathrm{E}^{0}$ group fed a high cholesterol diet for 10 and 15 wk (18 and 23 wk old), respectively. $N L D L$, Native LDL. antibodies to MDA-LDL reached a peak early in disease progression (Fig. 1). These data suggest that antibody formation culminates during the fatty streak stage; the finding of $\mathrm{IgG}$ as well as IgM antibodies is compatible with $\mathrm{T}$ cell help during the maturation of the $\mathrm{B}$ cell response. The titer changes of anti-MDA-LDL antibodies were not merely reflecting changes in immunoglobulin concentrations, since the latter remained unchanged during the study period (data not shown). The reduction in anti-MDA-LDL titers during progressing disease implies that no linear relationship exists between atherosclerosis and antibody titers to this oxLDL epitope.

$T$ cell-dependent antibody responses to $M D A-L D L$. The development of IgG antibodies suggested a role for T cell help in autoimmune responses to MDA-LDL. To specifically address this issue, we analyzed IgG subclasses of anti-MDALDL-reactive antibodies in the mice. Th1-type (proinflammatory) T cells stimulate antigen-specific B cells to synthesize antibodies of the IgG2a subclass, whereas Th2-type T cells induce secretion of IgG1 antibodies (35). These subclasses of anti-MDA-LDL antibodies were detected by an ELISA system, with MDA-LDL as the capture reagent and subclass-specific, enzyme-conjugated anti-IgG1 or anti-IgG2a as detector reagents.

As shown in Fig. 2, $\mathrm{E}^{0}$ mice fed a chow diet synthesized exclusively IgG2a antibodies in the early phase of disease (Figs. 2 and 3 ). The preferential production of IgG2a antibodies was not due to an increase in the total level of $\operatorname{IgG} 2 \mathrm{a}$, since this was unchanged during the study period (Fig. 2).

Surprisingly, the antibody subclass pattern was reversed completely in mice fed a high cholesterol diet (Figs. 2 and 3). Here, IgG antibodies in the early phase of disease (after $5 \mathrm{wk}$ on the diet) were of the IgG1 subclass, with no significant increase in IgG2a antibodies. Later on, IgG1 anti-MDA-LDL titers were lower on average but remained elevated significantly compared with controls throughout the study period (Fig. 2). As for IgG2a, the differences in IgG1 anti-MDA-LDL titers could not be explained by differences in the total levels of IgG1 (Fig. 2).

Since the high cholesterol diet contains cholic acid in addition to cholesterol, and since the severely hypercholesterolemic state may affect the functions of several organ systems, we also analyzed anti-MDA-LDL antibodies of mice fed a Western diet with $0.15 \%$ cholesterol and no cholic acid. These mice showed an intermediate pattern of autoantibodies, with formation of both IgG1 and IgG2a antibodies to MDA-LDL (Fig. 3).

$T$ cell subsets in the spleen of $E^{0}$ mice. The selective induction of $\mathrm{IgG} 2 \mathrm{a}$ antibodies in $\mathrm{E}^{0}$ mice suggests that $\mathrm{B}$ cell help was delivered preferentially by Th1 cells. In analogy, the selec- 

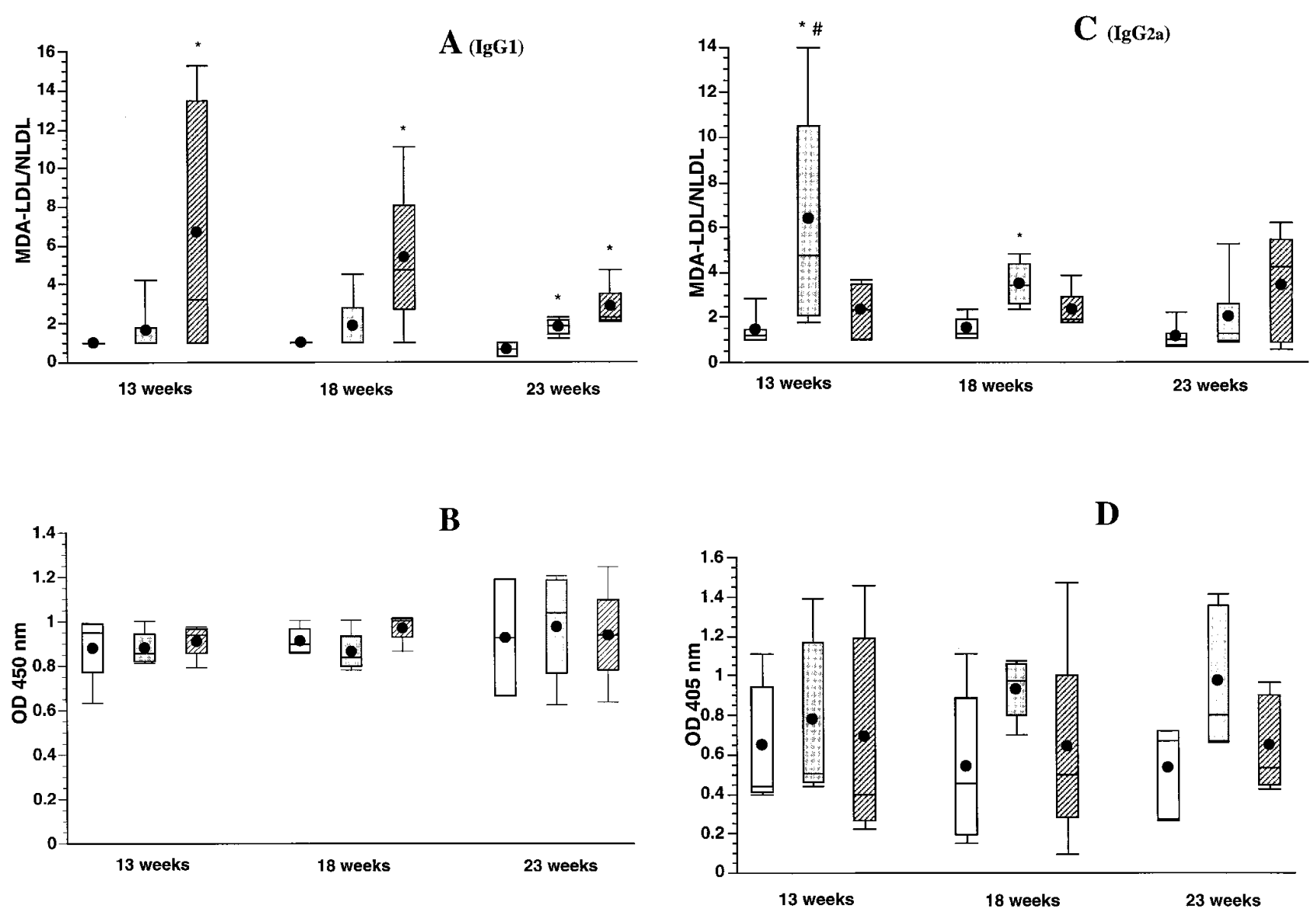

Figure 2. Box plots showing titers of $\operatorname{IgG} 1(A)$ and $\operatorname{IgG} 2 \mathrm{a}(C)$ antibodies to MDA-LDL, and total serum $\operatorname{IgG} 1(B)$ and $\operatorname{IgG} 2 \mathrm{a}(D)$ concentrations in $\mathrm{E}^{0}$ and $\mathrm{C} 57 \mathrm{BL} / 6$ mice. Sera were collected at the scheduled time point from C57BL/6 mice fed normal chow (white bars) and from $\mathrm{E}^{0}$ mice fed normal chow (gray bars) or a high cholesterol diet (striped bars). Boxes, whiskers, and dots are displayed as described in the citation to Fig. 1. $n=4-6$ for each group at each time point. *Significantly different from C57BL/6 mice, $P<0.05$. "Significantly different $(P<0.05)$ from the same group 18 and 23 wk of age. NLDL, Native LDL.

tive induction of IgG1 antibodies in cholesterol-fed $\mathrm{E}^{0}$ mice is compatible with an activation of Th2 cells. In addition to their expression of costimulatory cell surface molecules, Th1 cells provide help by secretion of IFN- $\gamma$, which promotes isotype switching from IgM to IgG2a. Th2 cells, on the other hand, secrete IL-4, which stimulates isotype switching to IgG1 (35). Therefore, we analyzed lymphoid organs of $\mathrm{E}^{0}$ mice for the presence of IFN- $\gamma$ - and IL-4-producing T cells.

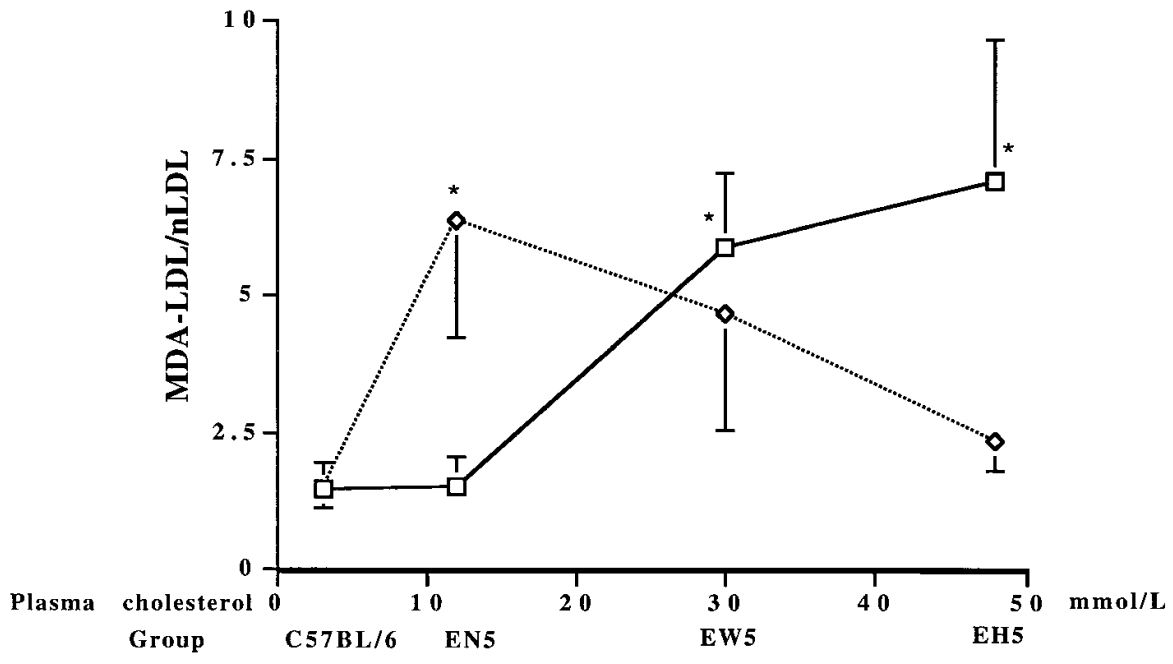

Figure 3. Relationship between plasma cholesterol levels (mmol/liter) and the titers of $\operatorname{IgG1}$ (open squares) and $\mathrm{IgG2a}$ (open diamonds) antibodies to MDA-LDL in $\mathrm{C} 57 \mathrm{BL} / 6$ and $\mathrm{E}^{0}$ mice. The latter were fed either normal chow (EN5), a Western diet with $0.15 \%$ cholesterol (EW5), or a high-cholesterol diet with $1.25 \%$ cholesterol (EH5) for $5 \mathrm{wk}$. Plasma cholesterol levels were $2.6 \pm 0.78 \mathrm{mmol} /$ liter for C57BL $/ 6$ mice and $12.8 \pm 1.97 \mathrm{mmol} /$ liter, $29.3 \pm 2.03 \mathrm{mmol} /$ liter and $48.1 \pm 5.61 \mathrm{mmol} /$ liter for $\mathrm{E}^{0}$ mice fed normal chow, Western diet, or the high cholesterol diet, respectively. $* P<0.05$ vs. C57BL/6 group. $n L D L$, Native LDL. 

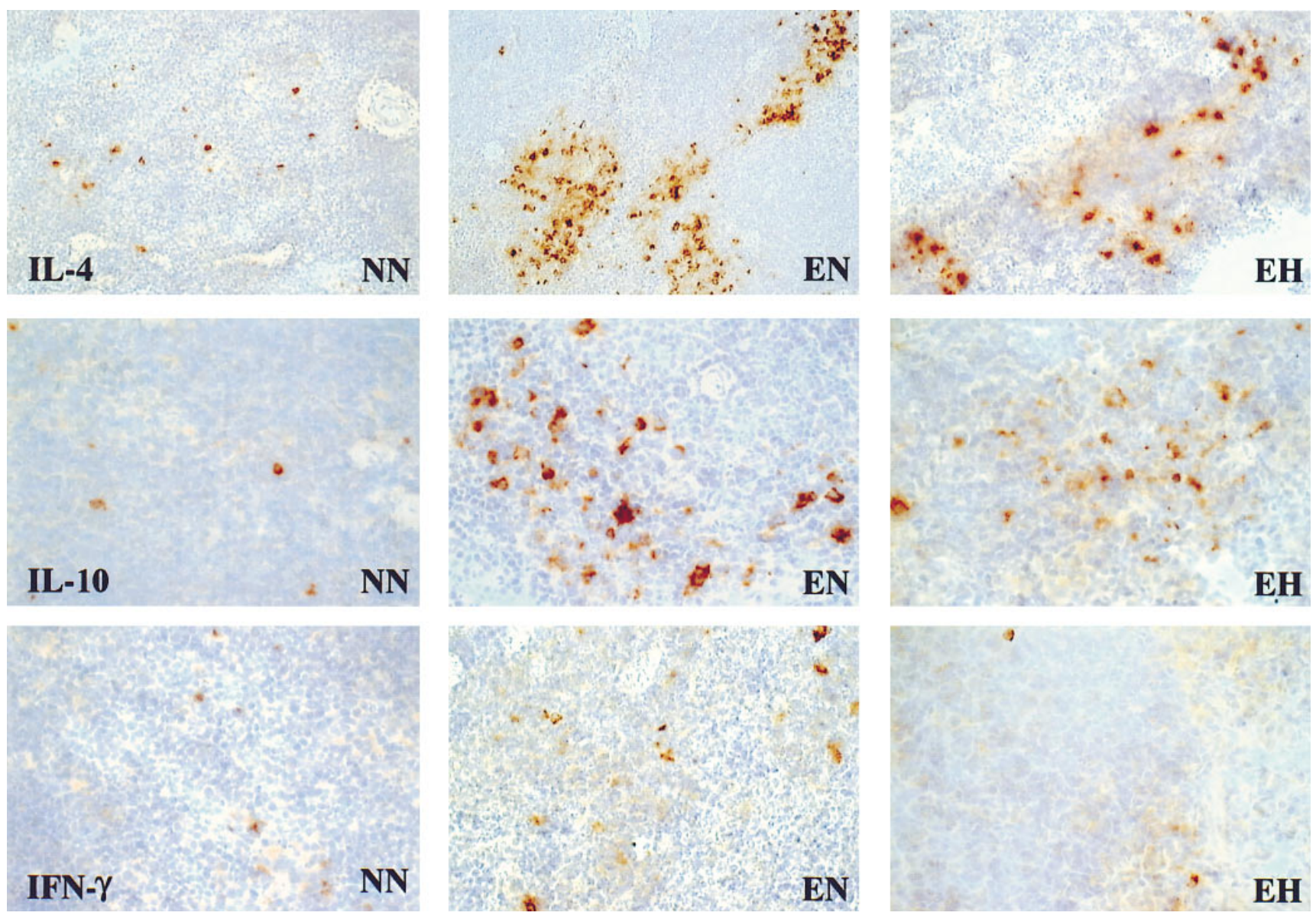

Figure 4. Immunohistochemical detection of cytokine-expressing T cells in the spleen of 13 -wk-old mice. C57BL/6 mice $(N N)$ were fed chow, and $\mathrm{E}^{0}$ mice were fed either chow $(E N)$ or a high cholesterol diet for $5 \mathrm{wk}(E H)$. Immunohistochemical staining using mAbs to IL-4 (top), IL-10 (middle), and IFN- $\gamma$ (bottom) followed by biotinylated secondary antibodies and peroxidase-avidin. $\times 200$ (top), and $\times 400$ (middle and bottom).

In comparison with wild-type C57BL/6 mice, spleens of $\mathrm{E}^{0}$ mice contained larger numbers of cytokine-producing $\mathrm{T}$ cells (Fig. 4, and Table III). In particular, the frequency of IL-4and IL-10-producing Th2 cells was increased significantly. Mice on the high cholesterol diet exhibited reduced frequencies of IFN- $\gamma$-secreting cells (Fig. 4, and Table III). In contrast, Th 2 cells producing IL-10, an IFN- $\gamma$ secretion inhibiting cytokine, were reduced to a lesser extent. The Th2/Th1 ratio went up from 4.4 in wild-type C57BL/6 mice, to 11.4 in $\mathrm{E}^{0}$ mice on a chow diet and 20.9 in $\mathrm{E}^{0}$ mice fed cholesterol (Table III). These findings imply that the lipid metabolic state of an animal modulates $\mathrm{T}$ cell differentiation and that this effect is reflected in the production of antibodies by B cells.

$T$ cell-dependent cytokine production in atherosclerotic plaques. Since $\mathrm{T}$ cells infiltrate atherosclerotic plaques of $\mathrm{E}^{0}$ mice, it was conceivable that activation of oxLDL-specific $\mathrm{T}$ cells occurs at this location as well as in lymphoid organs. To determine whether such an activation would involve Th1 or Th2 differentiation, we analyzed the expression of IFN- $\gamma$ and IL-4. However, immunocytochemical detection of IFN- $\gamma-$ or IL-4-producing cells was not technically possible, perhaps due to the high lipid content of the tissue specimens. Therefore, we used RT-PCR to detect IFN- $\gamma$ and IL-4 transcripts. In $\mathrm{E}^{0}$ mice fed standard chow, IFN- $\gamma$ but not IL-4 transcripts were de- tected in lesion RNA, implying the presence of activated Th1 but not Th2 cells (Fig. 5). In contrast, IL-4 mRNA was detectable together with IFN- $\gamma$ mRNA in lesions from mice fed a high cholesterol diet (Fig. 5). IL-4 transcripts were found in $50 \%$ of fatty streaks and $70 \%$ of fibrofatty plaques of choles-

Table III. Cytokine-secreting Cells in Spleen of 13-wk-old C57BL/6 Mice Fed Normal Chow and in $E^{0}$ Mice Fed Normal Chow or a High Cholesterol Diet for $5 \mathrm{wk}$

\begin{tabular}{llcccc}
\hline & \multicolumn{1}{c}{ IL-4 } & \multicolumn{1}{c}{ IL-10 } & IFN- $\gamma$ & IL-4/IFN- $\gamma$ & IL-10/IFN- $\gamma$ \\
\hline C57BL/6 & $23.2 \pm 3.1$ & $13.5 \pm 3.6$ & $5.3 \pm 1.1^{\S}$ & 4.4 & 2.6 \\
$\mathrm{E}^{0}$ chow & $71.3 \pm 14.2^{*}$ & $37.3 \pm 5.0^{*}$ & $6.3 \pm 1.1^{\S}$ & 11.4 & 6.0 \\
$\mathrm{E}^{0}$ hi-chol & $31.3 \pm 6.9^{\ddagger}$ & $29.0 \pm 6.1$ & $1.5 \pm 0.5$ & 20.9 & 19.3 \\
\hline
\end{tabular}

The number of IL-4-, IL-10-, and IFN- $\gamma$-positive cells were counted in 10 randomly selected fields per section at a final magnification of 400 . Values are positive cells per field (mean \pm SEM). Four to five mice were examined in each group. * Significant difference vs. C57BL/6, $P<0.05$; ${ }^{\ddagger}$ significant difference vs. $\mathrm{E}^{0}$ mice fed normal chow, $P<0.05$; ${ }^{\S}$ significant difference vs. $\mathrm{E}^{0}$ mice fed high cholesterol diet, $P<0.05$. hi-chol, High cholesterol diet. 


\section{EH5 EN10 EH10 Lnn Ctrl}

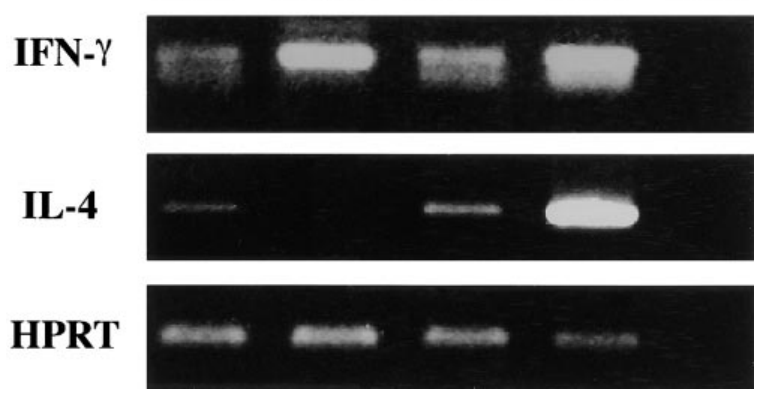

Figure 5. RT-PCR analysis of cytokine mRNA expression in lesions of $\mathrm{E}^{0}$ mice. The animals were fed either normal chow for $10 \mathrm{wk}$ (EN10) or a high cholesterol diet for 5 or $10 \mathrm{wk}$ (EH5 and EH10, respectively). EN10 and EH5 lesions were fatty streaks, and EH10 lesions were fibrofatty plaques. As positive controls, lymph node tissue mRNA ( $L n n)$ from $\mathrm{E}^{0}$ mice were analyzed, and as negative controls we used lesion mRNA but omitted the reverse transcription step $(C t r l)$. For $E N 10$, lesions were pooled from four mice; for $E H 5$, two parallel samples were studied, each of which contained pooled lesions from two mice; and for EH1O, three parallel samples were analyzed, each with lesions from one mouse. HPRT, Hypoxanthine phosphoribosyl transferase.

terol-fed mice, implying that the appearance of Th2 cells was due to the severely hypercholesterolemic state rather than to a specific phase of lesion development (Fig. 5).

\section{Discussion}

The results of this study show $(a)$ that the antibody response to oxidatively modified LDL is dependent partly on T cell help to antibody-producing B cells, (b) that the hypercholesterolemic state modulates the $\mathrm{T}$ cell response towards a Th2 type, and (c) that the Th1/Th2 switch occurs not only in lymphoid organs but also in the atherosclerotic plaque.

Autoantibodies to MDA-LDL and other epitopes on oxLDL are associated with atherosclerosis in humans and experimental animals. The occurrence of such a prominent systemic $B$ cell response to oxLDL in atherosclerotic subjects and the paucity of B cells in atherosclerotic lesions $(29,37,38)$ is paradoxical and suggested to us that $\mathrm{T}$ cells are involved in the development of anti-oxLDL antibody responses. We have found previously that $\mathrm{T}$ cells cloned from human atherosclerotic lesions recognize epitopes generated by oxidation of LDL (9). Therefore, it was possible that such $\mathrm{T}$ cells could provide help to $\mathrm{B}$ cells, resulting in a switch from IgM to IgG antibodies.

These data confirm previous reports (21) that IgG as well as IgM antibodies to MDA-LDL develop in hypercholesterolemic, atherosclerosis-prone $\mathrm{E}^{0}$ mice. The subclasses of $\mathrm{IgG}$ antibodies identified in the present report are indicative of $\mathrm{T}$ cell help in the differentiation of anti-MDA-LDL-producing B cells.

T cells have been shown to play a significant role in atherogenesis (39-41). This function is linked at least partly to their secretion of IFN- $\gamma$, an important macrophage-activating and proinflammatory cytokine $(42,43)$. IFN- $\gamma$ activates macrophages to produce cytokines, oxygen radicals, and metallopro- teinases, stimulates endothelial cells to express adhesion molecules, and reduces contractility and fibrogenesis in smooth muscle cells (44). Double-knockout mice lacking the IFN- $\gamma$ receptor as well as apo E develop much less atherosclerosis than $\mathrm{E}^{0}$ single-knockout mice (11). This implies that IFN- $\gamma$-secreting $\mathrm{T}$ cells play an aggravating role in atherogenesis.

IFN- $\gamma$ is produced only by a subset of T cells, the Th1 cell $(45,46)$. The other major subtype, the Th2 cells, secrete IL-4, IL-5, IL-10, and other cytokines which promote B cell activation, mast cell differentiation, and in general, humoral and allergic immune responses (46). In the mouse, both Th1 and Th2 cells can help B cells produce IgG antibodies. However, Th1 help results in $\mathrm{IgG} 2 \mathrm{a}$ antibodies, whereas Th2 help leads to IgG1 antibodies (45). Therefore, the subclasses of anti-MDALDL IgG serve as markers of the kind of T cell help involved in the immune response.

In chow-fed $\mathrm{E}^{0}$ mice, IgG antibodies to MDA-LDL were almost exclusively of the IgG2a subclass. This implies the involvement of Th1 help during B cell activation. Such a dominance of Th1/proinflammatory T cells is expected, both in view of the mouse strain used and the characteristics of the disease. The parental C57BL/6 strain is prone to Th1 activation and inflammatory responses and also to develop atherosclerosis when fed a high cholesterol diet. It should be interesting to evaluate antibody responses to oxLDL also in "Th2-prone" mouse strains such as BALB/c, which are more resistant to atherosclerosis (47).

Atherosclerosis is associated with Th1-type responses: IFN- $\gamma$ and IL- 2 mRNA are expressed in all advanced human plaques $(42,43)$, whereas IL-4 expression is found only in a minority of human plaques and at apparently lower mRNA and protein levels (our unpublished observations). In this study, we detected IFN- $\gamma$ but not IL-4 transcripts in the lesions of chowfed $\mathrm{E}^{0}$ mice. Interestingly, plaque macrophages express IL-12, a cytokine that specifically stimulates Th1 differentiation of $\mathrm{T}$ cells (48). All these findings point to a Th1 predominance among plaque T cells, and it is possible that the Th1 help to B cell antibody production observed in this study represents to a significant extent Th1 activation in atherosclerotic plaques.

To our surprise, the anti-MDA-LDL isotype switch was different in severely hypercholesterolemic $\mathrm{E}^{0}$ mice. When such mice were fed a diet containing $0.15 \%$ cholesterol, IgG1 antibodies to MDA-LDL increased, while IgG2a antibodies were decreased compared with chow-fed $\mathrm{E}^{0}$ mice. In mice fed $1.25 \%$ cholesterol, anti-MDA-LDL antibodies were almost exclusively of the Th2-dependent IgG1 isotype. The switch in isotype was associated with an increased number of Th2 cells in the spleen of these mice. In fact, there was a correlation between the plasma cholesterol level and the Th2/Th1 ratio. High antigen concentrations have been reported to induce Th2 responses $(49,50)$, and it is possible that the increasing levels of oxLDL during hypercholesterolemia preferentially induced Th2 activation.

The Th2 bias associated with severe hypercholesterolemia could either be antigen-specific or due to a generalized effect of the hypercholesterolemic state on $\mathrm{T}$ cell differentiation. Two lines of evidence point towards the former rather than the latter mechanism. First, there was no difference in the total levels of IgG1 or IgG2a antibodies between $\mathrm{E}^{0}$ mice on high cholesterol diet or chow, or between $\mathrm{E}^{0}$ and $\mathrm{C} 57 \mathrm{BL} / 6$ mice. Second, no strong bias towards a Th2-driven antibody response could be seen when hypercholesterolemic $\mathrm{E}^{0}$ mice were 
immunized with human immunoglobulin (A. Nicoletti and G.K. Hansson, unpublished observations). Therefore, although it is not ruled out completely, it appears less likely that hypercholesterolemia affects $\mathrm{T}$ cell responses in general. Instead, it is likely that the specific immune response to oxLDL switches to Th2-dependent B cell activation when the antigen reaches high levels in the lymphoid organs.

Th1 and Th2 cells reciprocally inhibit each other, IL-10 downregulating Th1, and IFN- $\gamma$ inhibiting Th2 activation (45, 50). Therefore, the reduction of Th1 cells and Th1-dependent anti-MDA-LDL production in severe hypercholesterolemia could be a consequence of the Th2 induction. Alternatively, Th1 cells could be more sensitive to inhibition by oxLDL or the hypercholesterolemic state, or secondarily affected by oxLDL-induced inhibition of macrophages (51).

T cells secreting IFN- $\gamma$ appear in atherosclerotic lesions as well as in lymphoid organs, and it is conceivable that $\mathrm{T}$ cell trafficking between these two sites is intrinsic to the disease process. The appearance of IL-4 transcripts in the lesions of severely hypercholesterolemic mice shows that the systemic switch towards a Th2 response is reflected in the T cell population of the artery. This implies that changes in the autoimmune response to oxLDL associated with hypercholesterolemia affects cytokine secretion in the lesion itself-and therefore probably the progression of the disease.

This could explain the seemingly paradoxical effects of immune defects on atherosclerosis in gene-targeted murine models. For instance, immune-deficient $\mathrm{E}^{0} \times \mathrm{RAG}^{0}$ (for recombination activator gene) double-knockout mice develop $40 \%$ less atherosclerosis than immunocompetent single-knockout $\mathrm{E}^{0}$ mice when fed standard chow, but this difference is eliminated when the mice are fed a cholesterol-rich diet (12). In the moderate hypercholesterolemia of $\mathrm{E}^{0}$ mice fed normal chow, proatherogenic Th1 responses are likely to prevail. The severely hypercholesterolemic condition of fat-fed mice should be associated with a switch to $\mathrm{Th} 2$, which might affect lesion development to a much lesser extent. This possibility emphasizes the need for considering higher-level interactions when analyzing relationships between complex systems such as the immune system and metabolism.

It will now be interesting to analyze the role of functional $\mathrm{T}$ cell subsets in the development of atherosclerosis in humans. However, one must be cautious when extrapolating from mice to humans, since lipoprotein metabolism differs significantly between the two species (52), and since the distinction between Th1 and Th2 responses may not be as clear-cut in humans as in the mouse (53).

In conclusion, our results point to a cooperation between $\mathrm{T}$ and $B$ cells in the autoimmune response to oxLDL and identify a link between cholesterol metabolism and the activation of Th cells in lymphoid organs and atherosclerotic lesions. It will now be important to determine whether immune responses to oxLDL can be modulated by treatment and whether such an approach can be used to reduce atherosclerosis.

\section{Acknowledgments}

We thank Dr. Antonino Nicoletti for stimulating discussions, Ingrid Törnberg for mRNA preparations, Kerstin Carlson for LDL preparations, and Karin Husman for measuring serum cholesterol.

Our work was supported by the Swedish Medical Research Council (project 6816), the Swedish Heart-Lung Foundation, the Johnson,
Wallenberg, and Hedlund Foundations, King Gustaf V 80th Anniversary and King Gustaf V and Queen Viktoria Foundations, and AFA Research Fund.

\section{References}

1. Steinberg, D., S. Parthasarathy, T.E. Carew, J.C. Khoo, and J.L. Witztum. 1989. Beyond cholesterol: modifications of low-density lipoprotein that increase its atherogenicity. N. Engl. J. Med. 320:915-924.

2. Witztum, J.L., and D. Steinberg. 1991. Role of oxidized low density lipoprotein in atherogenesis. J. Clin. Invest. 88:1785-1792.

3. Terkeltaub, R., C.L. Banka, J. Solan, D. Santoro, K. Brand, and L.K. Curtiss. 1994. Oxidized LDL induces monocytic cell expression of interleukin-8, a chemokine with T-lymphocyte chemotactic activity. Arterioscler. Thromb. 14: 47-53.

4. Quinn, M.T., S. Parthasarathy, L.G. Fong, and D. Steinber. 1987. Oxidatively modified low density lipoproteins: a potential role in recruitment and retention of monocyte/macrophages during atherogenesis. Proc. Natl. Acad. Sci. USA. 84:2995-2998.

5. Kume, N., M.I. Cybulsky, and M.A. Gimbrone. 1992. Lysophosphatidylcholine, a component of atherogenic lipoproteins, induces mononuclear leukocyte adhesion molecules in cultured human and rabbit arterial endothelial cells. J. Clin. Invest. 90:1138-1144.

6. Frostegård, J., J. Nilsson, A. Haegerstrand, A. Hamsten, H. Wigzell, and M. Gidlund. 1990. Oxidized low density lipoprotein induces differentiation and adhesion of human monocytes and the monocytic cell line U937. Proc. Natl. Acad. Sci. USA. 87:904-908.

7. Cathcart, M.K., D.W. Morel, and G.M. Chisolm. 1985. Monocytes and neutrophils oxidize low density lipoprotein making it cytotoxic. J. Leukocyte. Biol. 38:341-350.

8. Krieger, M., S. Acton, J. Ashkenas, A. Pearson, M. Penman, and D. Resnick. 1993. Molecular flypaper, host defense, and atherosclerosis. J. Biol. Chem. 268:4569-4572.

9. Stemme, S., B. Faber, J. Holm, O. Wiklund, J.L. Witztum, and G.K. Hansson. 1995. T lymphocytes from human atherosclerotic plaques recognize oxidized LDL. Proc. Natl. Acad. Sci. USA. 92:3893-3897.

10. Smith, J.D., E. Trogan, M. Ginsberg, C. Grigaux, J. Tian, and M. Miyata. 1995. Decreased atherosclerosis in mice deficient in both macrophage colony-stimulating factor (op) and apolipoprotein E. Proc. Natl. Acad. Sci. USA. 92:8264-8268.

11. Gupta, S., A.M. Pablo, X.-c. Jiang, N. Wang, A.R. Tall, and C. Schindler. 1997. IFN- $\gamma$ potentiates atherosclerosis in ApoE knock-out mice. J. Clin. Invest. 99:2752-2561.

12. Dansky, H.M., S.A. Charlton, M.M. Harper, and J.D. Smith. 1997. T and B lymphocytes play a minor role in atherosclerotic plaque formation in the apolipoprotein E-deficient mouse. Proc. Natl. Acad. Sci. USA. 94:4642-4646.

13. Roselaar, S.E., G. Schonfeld, and A. Daugherty. 1995. Enhanced development of atherosclerosis in cholesterol-fed rabbits by suppression of cellmediated immunity. J. Clin. Invest. 96:1389-1394.

14. Paton, P., A. Tabib, R. Loire, and R. Tete. 1993. Coronary artery lesions and human immunodeficiency virus infection. Res. Virol. 144:225-231.

15. Capron, L., Y.U. Kim, C. Laurian, P. Bruneval, and J.N. Fiessinger. Atheroembolism in HIV-positive individuals. Lancet. 340:1039-1040.

16. Marks, C., and S. Kuskov. Pattern of arterial aneurysms in acquired immunodeficiency disease. World J. Surg. 19:127-132.

17. Ylä-Herttuala, S., W. Palinski, S.W. Butler, S. Picard, D. Steinberg, and J.L. Witztum. 1994. Rabbit and human atherosclerotic lesions contain IgG that recognizes epitopes of oxidized LDL. Arterioscler. Thromb. 14:32-40.

18. Palinski, W., M.E. Rosenfeld, S. Ylä-Herttuala, G.C. Gurtner, S.A. Socher, S.W. Butler, S. Parthasarathy, T.E. Carew, D. Steinberg, and J.L. Witztum. 1989. Low density lipoprotein undergoes oxidative modification in vivo. Proc. Natl. Acad. Sci. USA. 86:1372-1376.

19. Bergmark, C., R. Wu, U. de Faire, A.K. Lefvert, and J. Swedenborg. 1995. Patients with early-onset peripheral vascular disease have increased levels of autoantibodies against oxidized LDL. Arterioscler. Thromb. Vasc. Biol. 15: $441-445$.

20. Salonen, J.T., S. Ylä-Herttuala, R. Yamamoto, S. Butler, H. Korpela, R. Salonen, K. Nyyssänen, W. Palinski, and J.L. Witztum. 1992. Autoantibody against oxidised LDL and progression of carotid atherosclerosis. Lancet. 339: 883-887.

21. Palinski, W., S. Hörkkö, E. Miller, U.P. Steinbrecher, H.C. Powell, L.K. Curtiss, and J.L. Witztum. 1996. Cloning of monoclonal autoantibodies to epitopes of oxidized lipoproteins from apolipoprotein E-deficient mice. Demonstration of epitopes of oxidized low density lipoprotein in human plasma. $J$. Clin. Invest. 98:800-814.

22. Palinski, W., E. Miller, and J.L. Witztum. 1995. Immunization of low density lipoprotein (LDL) receptor-deficient rabbits with homologous malondialdehyde-modified LDL reduces atherogenesis. Proc. Natl. Acad. Sci. USA. 92: $821-825$.

23. Ameli S., A. Hultgårdh-Nilsson, J. Regnström, F. Calara, J. Yano, B. 
Cercek, P.K. Shah, and J. Nilsson. 1996. Effect of immunization with homologous LDL and oxidized LDL on early atherosclerosis in hypercholesterolemic rabbits. Arterioscler. Thromb. Vasc. Biol. 16:1074-1079.

24. Nityanand, S., C. Bergmark, U. de Faire, J. Swedenborg, G. Holm, and A.K. Lefvert. 1995. Antibodies against endothelial cells and cardiolipin in young patients with peripheral atherosclerotic disease. J. Int. Med. 238:437-443.

25. Uusitupa, M.I.J., L. Niskanen, J. Luoma, P. Vilja, M. Mercuri, R. Rauramaa, and S. Ylä-Herttuala. 1996. Autoantibodies against oxidized LDL do not predict atherosclerotic vascular disease in non-insulin-dependent diabetes mellitus. Arterioscler. Thromb. Vasc. Biol. 16:1236-1242.

26. Nakashima, Y., A.S. Plump, E.W. Raines, J.L. Breslow, and R. Ross. 1994. ApoE-deficient mice develop lesions of all phases of atherosclerosis throughout the arterial tree. Arterioscler. Thromb. 14:133-140.

27. Piedrahita, J.A., S.H. Zhang, J.R. Hagaman, P.M. Oliver, and N. Maeda. 1992. Generation of mice carrying a mutant apolipoprotein E gene inactivated by gene targeting in embryonic stem cells. Proc. Natl. Acad. Sci. USA. 89:4471-4475.

28. Plump, A.S., J.D. Smith, T. Hayek, K. Aalto-Setälä, A. Walsh, J.G. Verstuyft, E.M. Rubin, and J.L. Breslow. 1992. Severe hypercholesterolemia and atherosclerosis in apolipoprotein E-deficient mice created by homologous recombination in ES cells. Cell. 71:343-353.

29. Zhou, X., S. Stemme, and G.K. Hansson. 1996. Evidence for a local immune response in atherosclerosis. CD4+ T cells infiltrate lesions of apo E-deficient mice. Am. J. Pathol. 149:359-366.

30. Daugherty, A., E. Puré, D. Delfel-Butteiger, J. Leferovich, and S.E. Roselaar. 1997. The effects of total lymphocyte deficiency on the extent of atherosclerosis in apolipoprotein E-/- mice. J. Clin. Invest. 100:1575-1580.

31. Palinski, W., V. Ord, A.S. Plump, J.L. Breslow, D. Steinberg, and J.L. Witztum. 1994. ApoE-deficient mice are a model of lipoprotein oxidation in atherogenesis: demonstration of oxidation-specific epitopes in lesions and high titers of autoantibodies to malondialdehyde-lysine in serum. Arterioscler. Thromb. 14:605-616.

32. Palinski, W., S. Ylä-Herttuala, M.E. Rosenfeld, S.W. Butler, S.A. Socher, S. Parthasarathy, L.K. Curtiss, and J.L. Witztum. 1990. Antisera and monoclonal antibodies specific for epitopes generated during oxidative modification of low density lipoprotein. Arterioscler. Thromb. 10:325-335.

33. Zinkernagel, R.M., and P.C. Doherty. 1974. Restriction of in vitro T cell-mediated cytotoxicity in lymphocytic choriomeningitis within a syngeneic and semiallogeneic system. Nature. 248:701-702.

34. Matis, L.A. 1990. The molecular basis of T cell specificity. Annu. Rev. Immunol. 8:65-82.

35. Snapper, C.M., and F.D. Finkelman. 1993. Immunoglobulin class switching. In Fundamental Immunology. 3rd ed. W.E. Paul, editor. Raven Press, Ltd., New York. 837-863.

36. Sander, B., I. Hoiden, U. Andersson, E. Möller, J.S. Abrams. 1993. Similar frequencies and kinetics of cytokine producing cells in murine peripheral blood and spleen. Cytokine detection by immunoassays and intracellular immunostaining. J. Immunol. Methods. 166:201-214.
37. Jonasson, L., J. Holm, O. Skalli, G. Bondjers, and G.K. Hansson. 1986. Regional accumulations of T cells, macrophages, and smooth muscle cells in the human atherosclerotic plaque. Arteriosclerosis. 6:131-138.

38. Roselaar, S.E., P.X. Kakkanathu, A. Daugherty. 1996. Lymphocyte populations in atherosclerotic lesions of apo $\mathrm{E}-/-$ and LDL receptor -/mice. Decreasing density with disease progression. Arterioscler. Thromb. Vasc. Biol. 16:1013-1018.

39. Hansson, G.K. 1994. Immunological control mechanisms in plaque formation. Basic. Res. Cardiol. 1:41-46.

40. Hansson, G.K., and P. Libby. 1995. The role of the lymphocyte. In Atherosclerosis and Coronary Artery Disease. Vol. 1. V. Fuster, R. Ross, and E.J. Topol, editors. Lippincott-Raven Publishers, Philadelphia/NewYork. 557-568.

41. Hansson, G.K. 1997. Cell-mediated immunity in atherosclerosis. Curr. Opin. Lipidol. 8:301-311.

42. Hansson, G.K., J. Holm, and L. Jonasson. 1989. Detection of activated T lymphocytes in the human atherosclerotic plaque. Am. J. Pathol. 135:169-175.

43. Geng, Y.J., J. Holm, S. Nygren, M. Bruzelius, S. Stemme, and G.K. Hansson. 1995. Expression of macrophage scavenger receptor in atherosclerosis. Relationship between scavenger receptor isoforms and the $\mathrm{T}$ cell cytokine, interferon- $\gamma$. Arterioscler. Thromb. Vasc. Biol. 15:1995-1202.

44. Hansson, G.K., V. Stemme, and T. Yokota. 1997. Cytokines and the cardiovascular system. In Cytokines in Health and Disease. 2nd ed. D. Remick and J. Friedland, editors. Lippincott-Raven Publishers, Philadelphia. 507-517.

45. Mosmann, T.R., and R.L. Coffman. 1989. TH1 and TH2 cells: differen patterns of lymphokine secretion lead to different functional properties. Annu. Rev. Immunol. 7:145-173.

46. Romagnani, S. 1997. The Th1/Th2 paradigm. Immunol. Today. 18:263-266.

47. Paigen, B., A. Morrow, C. Brandon, D. Mitchell, and P.A. Holmes. 1985. Variation in susceptibility to atherosclerosis among inbred strains of mice. Atherosclerosis. 57:65-73.

48. Uyemura, K., L. Demer, S.C. Castle, D. Jullien, J.A. Berliner, M.K. Gately, R.R. Warrier, N. Pham, A.M. Fogelman, R.L. Modlin. 1996. Cross-regulatory roles of interleukin (IL)-12 and IL-10 in atherosclerosis. J. Clin. Invest. 97:2130-2138

49. Hosken, N.A., K. Shibuya, A.W. Heath, K.M. Murphy, and A. O'Garra 1995. The effect of antigen dose on CD4+ T helper cell phenotype development in a T cell receptor- $\alpha \beta$ transgenic model. J. Exp. Med. 182:1579-1584

50. Constant, S.L., and K. Bottomly. 1997. Induction of CD4+ T cell responses: the alternative approaches. Annu. Rev. Immunol. 15:297-322.

51. Hamilton, T.A., G.P. Ma, and G.M. Chisolm. 1990. Oxidized low density lipoprotein suppresses the expression of tumor necrosis factor-alpha mRNA in stimulated murine peritoneal macrophages. J. Immunol. 144:23432350.

52. Witztum, J.L. 1993. Murine models for study of lipoprotein metabolism and atherosclerosis. J. Clin. Invest. 92:536-537.

53. Romagnani, S. 1994. Lymphokine production by human T cells in disease states. Annu. Rev. Immunol. 12:227-257. 